\title{
The Journey to Gender-Responsive Budgeting: Lessons Learned from Higher Education
}

\author{
Chiara Oppi ${ }^{1, *(D)}$, Caterina Cavicchi ${ }^{2}$ and Emidia Vagnoni ${ }^{2}(\mathbb{D}$ \\ 1 Center for Socio-Economic Dynamics and Co-operation, University of Bergamo, 24127 Bergamo, Italy \\ 2 Department of Economics and Management, University of Ferrara, 44121 Ferrara, Italy; \\ caterina.cavicchi@unife.it (C.C.); emidia.vagnoni@unife.it (E.V.) \\ * Correspondence: chiara.oppi@unibg.it; Tel.: +39-0532-455082
}

Citation: Oppi, C.; Cavicchi, C.; Vagnoni, E. The Journey to Gender-Responsive Budgeting: Lessons Learned from Higher Education. Sustainability 2021, 13 , 2019. https://doi.org/10.3390/ su13042019

Academic Editor: Benedetta Siboni Received: 28 December 2020

Accepted: 11 February 2021

Published: 13 February 2021

Publisher's Note: MDPI stays neutral with regard to jurisdictional claims in published maps and institutional affiliations.

\begin{abstract}
The United Nations Sustainable Development Goals Agenda includes gender equality as one of its 17 goals and emphasizes the importance of supporting women's empowerment to meet the SDGs. Gender-responsive budgeting (GRB) can help achieve gender equality in organizations, but there continue to be limitations on exploiting its full potential. Further research is needed, especially in the public sector and at higher education institutions. This paper investigates the development of the GRB process and the related reporting practices, as well as the potential to fully integrate it into the university's strategic policies at the University of Ferrara. The paper is based on a qualitative content analysis of annual GRB reports from 2011 to 2018. The results show that, during this period, GRB at the university changed from playing an accountability role to having a performance measurement role. Although GRB has become more relevant inside the organization, the extent of the integration with the university strategy and the budgeting cycle remains limited, which hampers the strategic relevance of GRB.
\end{abstract}

Keywords: gender-responsive budgeting; gender-responsive budgeting report; higher education institutions; content analysis; Italy; sustainable development

\section{Introduction}

Higher education institutions (HEIs) seek to legitimize their actions on sustainability issues by reporting on their activities related to sustainable development, communicating strategies, actions, efforts, and progress [1]. While sustainability reporting has mainly focused on economic and environmental issues, understanding of the social perspective is still rather shallow and requires further investigation [2]. Among the social issues that are particularly relevant to HEIs is gender equality (GE), which is also one of the United Nations (UN) Sustainable Development Goals (SDGs). Fully delivering on these goals includes reaching GE, which is tied to a comprehensive social responsibility [3]. Many international and European institutions have released guidelines, directives, and recommendations aimed at promoting GE, such as the EU Gender Action Plan 2016-2020, which focuses on promoting gender budgeting at both the national and local levels in EU countries [4]. Regarding gender-responsive budgeting (GRB), the OECD [5] has emphasized the importance of GRB in delivering on Goal 5 (Gender Equality) of the UN Sustainable Development Agenda by giving women equal access to economic resources, empowering them through technology, and reinforcing government interventions in terms of policy and legislation to ensure GE. To this end, "mainstreaming gender 'visibility' throughout the budget cycle-from formulation to monitoring and reporting - ensures accountability for policy commitments to gender equality" [5] (p. 27). Therefore, addressing the topic and contributing to the UN and EU goals are important targets, as in achieving GE, institutions can advance the sustainable development agenda [6]. Relevant links have been identified between the SDG 5 related to GE and the SDG agenda. Razavi points out that targets of the SDG 5 are complemented by other targets. She argues [7] (p.30) "complementing the target on unpaid domestic and 
care work is a target for achieving universal and equitable access to safe and affordable drinking water under Goal 6 (6.1). Other strategic elements such as full and productive employment/decent work for all women and men, and equal pay for work of equal value appear under Goal 8 (8.5), while access to social protection "for all" appears under Goal 1 (1.3)." To contribute to sustainable goals, gender inequalities need to be addressed from the economic, social, and environmental perspectives: women have less access to economic and political leadership, suffer income disparities, and gender gap. Despite being more sensitive than men to environmental issues women have less opportunities to be appointed in green jobs and top positions that could positively affect environmental policies [8]. To promote a transformative change towards GE, Odera and Mulusa [9] encourage investments in support of GE. They also argue that an analysis of the public spending impact is fundamental to detect inequalities. In this context, they refer to GRB as a process that can help support these activities [9]. Various sources in the literature indicate that GRB aims to redress "existing gender inequalities" by challenging current economic models that do not account for the impact public policies have in allocating resources to females and males. Therefore, GRB aims to enhance GE through assessing the effectiveness of such policies on different genders and contributing to a better allocation of public resources to meet these different needs [10] (p.3). Thus, GRB entails two complementary perspectives: The first relates to techniques and tools that are foundational in decision-making related to resource allocation; the second relates to the cultural change required to ensure that gender issues are visible and addressed in ways that will promote GE [11]. Sustainability literature in private and public organizations has encouraged scholars to develop sustainability assessment, reporting, management, and control in an integrated manner (see, e.g., Maas et al. [12]), especially in the context of HEIs. Particularly, integrating sustainability reporting in the strategic policies of universities has been emphasized as a means of promoting effective change toward sustainable development $[13,14]$.

Consequently, GRB to promote sustainable GE has been described as a possible tool to integrate a well-suited gender perspective in universities' strategic policies. Scholars such as Rothe et al. [15] have put forward recommendations to support this process in academia.

In the Italian context, HEIs still do not have specific measures to protect the less represented gender and generally focus simply on meeting the constitutional principle of GE [16]. Because detailed legislation is lacking at the national level, the drafting of rules on equal opportunities in statutes and regulations has been delegated to the universities themselves. Recently, however, there have been several recommendations and guidelines to incentivize the adoption of a gender perspective and integrate it into performance measurement [17], while also stressing the relevance of the role of equal opportunities bodies [18], particularly with regard to a GRB process. Both the Italian central government (e.g., the Ministry of Education, University and Research) [19] and other national institutions have published specific recommendations for HEIs about the relevance of GRB for a strategic change $[20,21]$. Such consideration has given the topic increased attention.

Although GRB is gaining practical relevance despite being less used than expected [5], more research is still needed. Managerial and management control literature has traditionally neglected the topic. Concerning HEIs, research has addressed the mechanisms preventing women from becoming fully involved in academia $[22,23]$ and emphasized the need to take action to combat the under-representation of women in science [24]. With respect to the Italian university context, Galizzi and Siboni's [25] study of Positive Action Plans (PAPs) and the positive actions implemented to deal with inequality calls for a "future 'gender agenda'" that includes an analysis of the lessons learned for positive actions, as well as their results and impacts. Although some research has been conducted in HEIs at international level in the last few decades $[15,26]$, gender and academia remain a scantly debated topic. Particularly lacking, is the link between strategic management and management control processes in the light of the changing organizational and extra-organizational contexts [27]. This gap in research underscores the importance of debating the relevance of GRB for HEIs. Relatedly, the present study investigates the case of GRB at the University 
of Ferrara (UniFe). Specifically, it investigates the development of a GRB process and the related reporting practices, as well as discussing the potential to fully integrate GRB into the university's strategic policies.

\section{Literature Review}

Accounting literature has traditionally addressed gender issues and focused on how women in accounting professions experience difficulties when entering the profession and seeking greater empowerment in their roles [28,29], as well as the relevant cultural aspects [30]. Literature has also explored how discrimination at institutions threatens women's careers [31] and which factors preclude female accountants from developing in their careers $[32,33]$.

In the past few decades, accounting research has started paying increasing attention to the HEI context. While some studies investigate accounting students and education patterns (e.g., Wessels and Steenkamp [34]), others look to academic careers more broadly. In this context, some research has shown evidence of the low numbers of women among academic staff [35], also with specific regard to the accounting field [28]. Others, such as Baldarelli et al. [36], have examined the gender distribution of authors in journals in the accounting field. Further studies report the vertical segregation that female academics experience $[22,23,37]$. Segregation has also been widely reported by empirical data: Since 2003, the triennial She Figures report has examined researchers' gender distribution in European HEIs $[24,38,39]$ and provided evidence of the under-representation of women throughout senior positions in academia [39]. It presents evidence of women having greater representation among students and graduates and in entry-level positions in academia. The number of women gradually decreases as seniority increases; thus, women are underrepresented among associate and full professors, as well as directors and deans and on boards, which reduces their ability to affect decision-making processes and the management of the university. This vertical segregation is common in EU countries, where female full professors account for less than $24 \%$ of all full professors [39]. In Italy, women face even greater difficulty, and the number of female full professors (slightly above $22 \%$ of the total number of full professors) is below the EU mean, which appears to confirm the existence of a glass ceiling effect [35]. Again, literature focusing on gender differences in academic performance has highlighted that higher relevance is attributed to publications, funding, and citation rates than to teaching activity, students' supervision, and administrative tasks [40,41], which gives male-dominated fields an advantage [42].

Accounting literature has mainly focused on women's roles and under-representation and approached them as individuals, while there has been very little research about organizations and their commitment to GE. For a long time, research paid little attention to practices that read reality through the lens of gender [25]. In drafting a "gender agenda" for research, Broadbent [43] and Siboni et al. [44] call for more accounting studies on the topic, while other authors emphasize the need to explore the HEI context in particular $[35,45]$. To support GE in HEIs, the literature has highlighted the importance of ensuring a strategic process that involves leadership and actions throughout all levels of an organization [46]. In particular, although performance measurement systems were traditionally considered gender-neutral, directing research toward strategic management and management control processes in a gender light has become ever more important [27]. Public budgets seem gender-neutral as they do not make specific reference to gender. However, revenue and expenditure decisions affect women and men differently, and ignoring such differences has been described as "gender blindness" [47]. Thus, there is a clear need for developing GRB [48].

GRB refers to a systemic approach that involves various instruments, techniques, and procedures to integrate the gender perspective into the overall budget process-from planning to reporting $[5,11,49]$. Since the mid-1980s, GRB has gained increasing relevance in multiple contexts and in public sector organizations [50], including at HEIs [3,51]. GRB is rooted in gender mainstreaming, understood as a strategy for promoting equal opportunity and disseminating the gender perspective in political choices by rethinking traditional 
decision-making processes. It makes the budget's impact on gender visible in order to reach GE through policy [52]. GRB is consistent with the need to rethink the budgeting approach and revise its structure by including gender perspective as a performance strategy to meet the goals of effectiveness, efficiency, and transparency [53]. GRB makes it possible to manage resources and assess the effectiveness and efficiency of interventions in light of GE, thereby deepening the processes implemented in the organization that contribute to delivering equal opportunities for the genders. Thus, GRB applies to multiple phases in planning and reporting processes seeking to overcome the narrow focus on the budgeting process alone [11]. Based on Rubin and Bartle [48], Steccolini [11] summarizes the approaches to GRB during its preparation and approval, execution, reporting, and auditing phases. In this regard, prior to budget implementation, GRB helps to incorporate gender policies and supports the aim of assessing gender needs; during budget execution, it provides gender-responsive guidelines on spending and outsourcing; and in the reporting phase, GRB supports the inclusion of a gender perspective in audits. Further, GRB requires the adoption of gender-responsive logic to guide strategic implementation, while it can assume the role of a practice using tools and techniques that support decision making.

In this vein, GRB assists internal management processes by contributing to the inclusion of gender-oriented strategies in the economic and financial, human resource management, responsibilities appointment, and evaluation processes. Since performance measurement systems in public organizations barely consider gender differences [27], which poses a challenge to the possibility of measuring short- and long-term results, as well as the impacts on the gender perspective, GRB supports the promotion of organizations awareness of the policies' consequences, which can spur a rethink of public policies [54]. In this way, the implementation of GRB recalls the Deming Cycle (adopted for HEIs from a sustainability perspective by Lukman and Glavič, [55]), which consists of a succession of policy planning activities, their implementation, external and internal reporting, evaluation, and control and focuses especially on the methods and effects of allocating resources to reach GE [48]. As an accountability tool, GRB addresses the need to report the results and impacts of the policies implemented by the organizations and supports spending review processes $[11,56,57]$. In addition, GRB serves public organizations' accountability practices by supporting communication with the stakeholders and reporting on both performance results and the use of resources. Thus, attention is paid to how expenses can have different impacts on women and men [58].

However, GRB does not have standardized characteristics and can take different forms and approaches in practice. For instance, some organizations amend their monitoring systems to track expenditure, while others restrict their efforts to accountability through a limited integration of the gender perspective into budgeting [59]. Literature has discussed the actual capacity of GRB to affect policy-making processes and policy outcomes regarding GE [60], but only a few researchers have investigated the patterns of how the gender perspective is integrated into budgets [48]. So far, there has been little evidence of any substantive impact on GE, and there is still a need for accounting research to examine the topic in greater depth, especially with regard to the role played by GRB in reaching GE, as well as gender-based performance indicators in public budgets [59].

In a recent paper, Steccolini [11] emphasizes the importance of institutionalizing GRB for it to reach its full potential. She highlights a series of challenges that can be identified in GRB implementation in the public sector: The availability of data and analytical capacities to interpret them, the centrality of gender logics guiding the political agenda, stakeholders involvement in and commitment to GE and awareness diffusion, the balance between standardizing practices and adapting to context and needs and considering other sources of inequality.

The importance of making inequalities visible has emerged also in HEIs. HEIs are starting to support taking action and are gradually challenging the legitimization of such inequalities [42]. Focusing on the European context, Rothe et al. [15] reported a series of recommendations for implementing GRB processes in academia. In this sense, the authors 
emphasized the need to support GRB implementation through an institutional framework that promotes, implements, coordinates and monitors GE objectives. To achieve this, the authors suggest to set strategic GE objectives integrated in all managerial instruments, as consistent measures. They also suggest implementing gender impact assessment processes resulting from the implemented policies [61]. They recognize the need to develop specific indicators to capture the progress toward GE, as well as the importance of collecting and disclosing data on a gender perspective. Making the annual GRB reports public might help to monitor such progress. The authors also emphasize the importance of linking the gender perspective to budgeting processes and performance evaluation [15]. In this regard, HEIs are required to revise their management control systems to include the gender perspective, to guarantee the achievement of GE objectives and to provide reliable information to support strategic processes. Thus, GRB has the potential to support strategic policy development in the planning, implementation, and evaluation phases [26]. Further, GRB encourages the analysis of budgeting decisions' differential impact on women and men [42] to enhance transparency and better management [15]. This is especially important to address the indirect gender discrimination that often follows when financial and managerial procedures advantage male dominated fields [62].

In the Italian context the GRB implementation that has gained attention, has been restricted to municipal and regional levels. For instance, recent studies by Galizzi et al. [10] and Del Gesso [63] focus on the adoption of GRB in local and regional governments. Others [64] explore similarities and differences in local entities' exercise of GRB. According to them, GRB practices at the local and regional levels in Italy follow three main steps: (i) context analysis, which calculates the demographic, social, and economic indicators of GE; (ii) analysis of local GE practices, which refers to the work-life balance, procurement policies, and gender empowerment and involves a consideration of expenditures to tackle gender disparities; and (iii) gender impact analysis of expenditures, as well as the assessment of budget impacts in terms of improvements to reach GE.

The specific context of Italian HEIs has not been widely considered, with GRB hardly gaining traction. In recent years, the national and EU projects (such as GenderTime, TRIGGER, PLOTINA, LeTSGEPs) that have been introduced aim to ensure GE in HEIs and they remind of GRB processes and GRB reports as means of supporting the GE objectives in Italy. These projects highlight the relevance of the HEI context in promoting research on GRB and its application in practice. Nevertheless, to date the literature has barely addressed GE in Italian HEIs recently. Galizzi and Siboni [25] considered GE disclosure through adopting PAPs in HEIs, while Mazzotta et al. [65] investigated GE in university governance boards and how gender diversity contributes to decision making. At present, however, GRB features in Italian HEIs could profit from further investigation.

\section{Research Setting and Method}

\subsection{GRB in Italian HEIs}

This research focuses on GRB implementation at Italian HEIs. In the context of Italy's public organizations, GRB process does not follow a specific normative provision, but is embedded in a series of regulations that underscore its importance. The Code of Equal Opportunities between Women and Men (Legislative Decree no. 198/2006 [66]), which came into force in 2006, was the first step toward the subsequent implementation of PAPs in public organizations. PAPs are three-year strategic documents that express GE objectives. According to the regulatory framework, PAPs also include measures to ensure "the removal of obstacles that, in practice, prevent the equal opportunities" for women and men ([66] art. 48). Thus, PAPs describe GE objectives, consistent actions (i.e., the positive actions) to be implemented, as well as the organization's targets and responsibilities. The objectives and actions included in PAPs are usually directed at ensuring well-being, promoting life-work balance, and challenging vertical and horizontal segregation in organizations.

In 2007 the Ministry of Public Administration and the Ministry for Equal Opportunities introduced a directive, "Measures to implement equality and equal opportunities 
between men and women in public organizations" [67], that indicated the need for public organizations to implement GRBs and to publish GRB reports, in the hope that these practices would become consolidated and thus incentivize the achievement of GE. The GRB report was later mentioned in Legislative Decree no. 150/2009 [17], which listed it among the instruments in the administrative performance cycle.

Following these normative provisions, a growing number of Italian HEIs have developed their own gender-responsive budgets in the past decade. While just one of the 97 HEIs [68]. the Italian HEIs include 67 state universities and 19 legally recognized non-state universities, as well as 11 legally recognized non-state universities offering distance learning) started implementing GRB and reported it in 2011, the number of institutions involved in this process increased to 13 by 2018 [69]. Although limited in number, these first attempts at GRB resulted in heterogeneous approaches, and HEIs tackled the aims of GRB in various ways. The majority of HEIs currently perform only a gender-sensitive analysis of the university context and publish GRB reports to highlight areas of disparity and segregation (among students, academic staff, technical-administrative staff, and governance bodies). A few have reported the outputs of implemented GE practices or provided evidence of how they have rescheduled interventions and activities in response to the gender needs highlighted and the performance measured. In this regard, HEIs have often intended GRB primarily as a reporting tool to be used in communication with stakeholders.

Considering the limited adoption of GRB processes, the central government and other institutions have recently published specific recommendations for HEIs to strengthen GRB's role, overcome its use exclusively as an accountability tool, and work toward exploiting its full potential. The Ministry of Education, University and Research (MIUR) [19] published recommendations for developing positive actions to pursue GE, while Directive 2/2019 of the Ministry of Public Administration [18] added the PAP as an annex to the Performance Plan, also mentioning the GRB report among the requirements for public administrations. Further, in 2019, the National Agency for Evaluating the University and Research System (ANVUR) aimed to incentivize HEIs toward gender-responsive logics in the performance and budget cycles and published guidelines for implementing GRB processes [20]. The Conference of Italian University Rectors (CRUI) also published specific guidelines for implementing GRB processes at HEIs [21]. These guidelines have reinforced the role of GRB in HEIs, providing practical suggestions to incentivize the implementation of the GRB process and fully integrate the GE perspective into the strategic process.

\subsection{The University of Ferrara}

This paper focuses on the case of the University of Ferrara (UniFe). UniFe is a state university located in Italy's Emilia-Romagna region. In 2018, it comprised 12 departments with a training offer of 30 bachelors and 45 master's degree courses, $13 \mathrm{PhD}$ courses, 31 medical specialization schools, and other types of post-degree education (e.g., first-level and second-level master's degree courses, as well as advanced courses). The number of UniFe students has increased over the past few years: from 15,501 in 2015 to 20,299 in 2018 to 22,937 in 2019. UniFe is now listed among the big Italian universities (over 20,000 students according to the subdivision of Censis [70]).

Considering the gender context at UniFe, some details are provided according to the MIUR database [71]. In the academic year 2019/2020 the majority of students were female (59.2\%); however, they report horizontal segregation: females account for less than $18.9 \%$ in engineering, manufacturing, and construction programs, while they constitute $91.2 \%$ of those enrolled in education degree courses and $70.9 \%$ in the arts and humanities field. Concerning academic staff, in 2019 (most recent available data) women accounted for $41.2 \%$ of the total, while vertical segregation emerges in that $55.1 \%$ of the research fellows, $53.0 \%$ of the researchers, $37.2 \%$ of the associate professors, and only $15.6 \%$ of the full professors are female academics. The predominance of male professors is even more pronounced in the STEM (science, technology, engineering, and mathematics) areas, where female associate and full professors represent $32.7 \%$ and $14.9 \%$, respectively. Vertical segregation 
also emerges considering managerial positions: only two of 12 Departments are led by women. Concerning technical and administrative staff, at UniFe females represent $69.1 \%$ of the employees. However, managerial positions report a gender rebalancing in that $50 \%$ of the positions are occupied by male and $50 \%$ by female appointees. This suggests that men, although under-represented in the category, face less difficulties in reaching higher positions. Given the above data, gender issues at UniFe mainly refer to the distribution of students and researchers across fields, to female presence in top-management positions, and at higher levels of the academic career.

\subsection{GRB at the University of Ferrara}

UniFe pursues its objective of GE through various figures and institutional bodies: A Rector's Deputy for Equal Opportunities, an Equality Council (EC), and a Single Guarantee Committee (SGC) in charge of promoting, monitoring, and reporting positive actions, while other bodies strive for specific goals that are also related to well-being and disabilities. GRB implementation is part of the SGC's responsibilities.

Since 2011, UniFe has identified its own strategies for GE by publishing a triennial PAP, of which the first edition focused on the 2011-2013 period. In 2012, in line with the aims of that PAP and consistent with positive actions, UniFe started a GRB process, thereby becoming the first Italian HEI to develop a gender-responsive budget. Aiming to account for all the policies implemented at the university and to promote equal opportunities, GRB implementation was supported through an annual publication, the GRB report. Specifically, UniFe has reported on GRB since 2012 to 2019 through dedicated publications released every year in the fall and referring to the previous year (e.g., in the fall of 2016, the report referred to 2015 and was published under the label of 2015 GRB report). The GRB report was initially linked to the university's sustainability strategy as it was produced in connection with UniFe's Social Report. Over time, it became an autonomous report thanks to top management's desire to increase attention to gender issues and establish a scientific committee with specialized competences. Such a committee would spearhead the evolution of the GRB report and establish a working group in charge of supporting data collection. These groups reported a stable composition over time, working under the Rector's mandate. The scientific committee is composed of academics acknowledged on gender issues (e.g., from managerial and regulatory perspectives), managers within the technical and administrative staff, and representatives of both EC and SGC. The working group is composed of employees on the technical and administrative staff and others related to the units involved in data collection (e.g., Personnel Office, Teaching Office, Students Office, Management Control Office, and Accounting Office). The groups' activities are coordinated by an administrative employee who acts as the UniFe Coordinator for the GRB report. Every year, the Coordinator and the scientific committee define a protocol for data collection which determines context analysis indicators, type of data, and deadlines for data gathering. The protocol describes the process through which the working group will collect data and they are synthesized by a Coordinator. The Coordinator also organizes meetings with units and actors in charge of implementing positive actions, to collect data on activities and actions' results. The Coordinator and the scientific committee are then tasked with drafting the GRB report, discussing it with governance bodies, and submitting it for approval to the Board of Directors (since 2016), after which the report is published.

Based on this, the GRB report development at UniFe has become an independent activity, which acts separately from other management control processes. Data collection for context analysis derives from manual and non-systematic procedures, while data on positive actions' results is collected through ad hoc meetings with the units involved in implementing the actions.

\subsection{The Method}

This paper focuses on GRB at UniFe. UniFe was chosen as setting for its role as the first Italian HEI to publish a GRB report, and for its recognized gender-sensitive approach to 
strategic development [65]. Using approaches similar to those in previous studies investigating disclosures about gender [72], the paper performs a content analysis of UniFe's disclosures about GRB in its GRB reports, analyzes the results by topic, and discusses them according to specific periods. Following the research process of Bengtsson [73], the authors performed a qualitative content analysis. In the planning phase, the authors decided to carry out data analysis using an inductive approach. Inductive content analysis was considered appropriate as there is a paucity of studies on the focal phenomenon, which makes it necessary to derive categories from the data [74]. Therefore, the aim of the content analysis was to investigate the development of GRB process and the related reporting practices, as well as to discuss the potential for fully integrating GRB into the university's strategy.

The sample primarily consisted of GRB reports published between 2012 and 2019 (i.e., covering the 2011-2018 period). The eight publications were analyzed in their entirety. At the time of data collection (June 2020), no more recent publications were available. Data collection was performed online as the publications were identified on the institutional website that contains a specific section with all the GRB reports (Publications may be accessed at http:/ / www.unife.it/progetto/equality-and-diversity/bilancio-di-genere (accessed on 23 November 2020). Some of the reports are only in Italian, but the 2013-2017 GRB reports are also available in English).

Thus, the authors identified categories through an inductive approach in their data analysis [75]. To increase validity, two researchers conducted the content analysis autonomously and discussed the results to find consensus [76]. The authors identified categories and sub-categories, as well the elements to be included in each of them [77]. The categories were identified to ensure internal homogeneity and external heterogeneity [78]. In line with the inductive approach and the aims of the analysis, the researchers defined and repeatedly revised the coding list [79] throughout the process to minimize cognitive changes during the analysis and to ensure reliability among the coders [80]. University regulations, in particular the PAPs and the Strategic Plans, were also collected and used as secondary sources of analysis to triangulate the data and diminish the potential effects of researcher bias [81]. The categories and sub-categories used in the case are shown in Table 1.

Table 1. Categories and sub-categories of the content analysis.

\begin{tabular}{cc}
\hline Categories & Sub-Categories \\
Context analysis & $\begin{array}{c}\text { Students, academic staff, technical and } \\
\text { administrative staff, and governance indicators }\end{array}$ \\
\cline { 2 - 2 } Positive action plan & She Figures indicators \\
\hline Description of positive actions & Positive action plan objectives \\
\hline Assessment of positive actions & Description of implemented positive actions \\
\hline Budget analysis & Indicators of positive actions' results \\
\hline Integration with strategy & Budget analysis of positive actions \\
\hline
\end{tabular}

\section{Results}

The results are presented in line with the categories identified in the content analysis. At UniFe, the GRB's features changed over time. The evolution of GRB (and the GRB reports) within UniFe aligned with a series of agreements with other institutions and university policy. The major milestones that led to changes in GRB are described in Table 2. 
Table 2. Gender-responsive budgeting (GRB) milestones at the University of Ferrara (UniFe).

\begin{tabular}{cc}
\hline Year & Milestones \\
\hline 2011 & $\begin{array}{c}\text { Implementation of GRBDecision to report GRB } \\
\text { annually, following the 2011-2013 Positive Action Plan (PAP) }\end{array}$ \\
\hline 2012 & $\begin{array}{c}\text { Collaboration with the MIUR's Statistics Office on context data collection and data } \\
\text { reliability }\end{array}$ \\
\hline 2012 & First GRB publication (2011 GRB report) as a separate chapter of the Social Report \\
\hline 2013 & First GRB publication as a standalone document (2012 GRB report) \\
\hline 2014 & $\begin{array}{r}\text { Publication of context indicators in line with the EU report She Figures to allow } \\
\text { benchmarking with national data, starting with the 2012 GRB report }\end{array}$ \\
\hline 2016 & $\begin{array}{r}\text { PAP contents are integrated into the university's Strategic Plan and Performance Plan } \\
\text { gender the equaly adopted UniFe Statute, approving the GRB report is one of the duties } \\
\text { of the Board of Directors }\end{array}$ \\
\hline 2017 & Adoption of a three-year structure in GRB reports, starting with the 2016 GRB report \\
\hline
\end{tabular}

Following its decision to implement GRB in 2011, UniFe sought to publish reliable context data and benchmarking at an international level in its 2012 and 2013 GRB reports. In the 2011-2013 PAP, the development of GRB was mentioned for the first time to support statistics related to GE. Initially published as a separate chapter within the Social Report (the 2011 GRB report), the GRB report became a standalone document the following year and has outlasted the Social Report, which was last issued in 2013-2014.

The 2014-2016 PAP designated GRB as a tool to monitor the positive actions put in place by the university and to support the controlling role of the two equality bodies, the EC and the SGC, tasked with implementing, monitoring, and reporting positive actions. The role of GRB was further reinforced in 2016 by the new UniFe Statute, which included the approval of the GRB report as one of the duties of the Board of Directors.

In 2016, following these provisions, UniFe adopted a three-year structure in GRB reports: "GRB is part of a cyclical process of planning, execution, monitoring and review of equal opportunities policies implemented by the University of Ferrara" (2017 GRB report, p. 13).

In this regard, UniFe oversaw different reporting activities based on the schedule laid out in the PAP: publication in the first year (the same as the first year of the PAP) with a focus on context analysis and budget baseline analysis; in the second year, the publication is more centered on accounting about the integration of GRB in strategic documents; and in the third year (referring to the last year of the PAP), reporting concerns an assessment of and expenses related to the positive actions. This approach was first taken with the 2016 GRB report, where reporting focused on the 2014-2016 PAP's assessment. The 2017 GRB report, associated with the first year of the 2017-2019 PAP, focused specifically on context analysis, and the 2018 GRB report centered its investigation on the interplay between GRB and strategic documents.

\subsection{Context Analysis}

Context analysis refers to the analysis of all the different people and groupings that work and study at UniFe. It covers students, academic staff, technical and administrative staff, and governance. Context analysis emerges as the main point of interest of the first reports, especially with regard to the 2011-2014 period, and accounts for about one-half of the total pages of these reports. In the 2015 GRB report, context analysis comprised about one-third of the total publication length as the report included both context analysis and the results of the positive actions put in place by UniFe, consistent with the 2014-2016 PAP and the monitoring role associated with GRB. 
In all the publications, context analysis focused on the number of women and men involved at all levels of UniFe and on their characteristics. The analysis of the university components was done separately. The context analysis usually starts with students before examining technical and administrative staff, academic staff, and governance.

Since the first GRB report, data has widely emphasized aspects worthy of attention in each of the categories. Among students, women have been evaluated as performing better and graduating sooner than men, and with higher grades. However, horizontal segregation in courses emerged, with women less represented in STEM and over-represented in fields such as education, arts, and humanities. The reports also found consequences in terms of lower employability of female students and lower salaries compared to their male colleagues after they graduated. Concerning technical and administrative staff, data reported a predominance of women requiring parental leaves and employed with parttime contracts, which suggests a major difficulty in women's work-life balance. Moreover, although women represent the majority of the technical and administrative staff, men more regularly reach top management positions. Therefore, males are proportionately better represented among managers than at lower employees' levels. Among the academic staff, the main issues are low representation of women in full professors' positions and in horizontal segregation, especially in STEM fields where barely any female academics are present. In addition, scarce female representation in top managers' positions (e.g., as deans or heads of departments) was found. In governance bodies female presence is usually limited to less reputed roles (i.e., students' representative in the Academic Senate) or to bodies dealing with equal opportunities topics (e.g., the EC and the SGC). These results emerged repeatedly in all GRB reports, with very few changes over time.

Following the specific issues highlighted in the data, the university paid particular attention to patterns of vertical and horizontal segregation in careers. It introduced additional indicators to monitor how technical and administrative staff and academic careers progressed, paying attention to the distribution of women and men's progression in the various fields. The indicators have increased over time: in the 2011 GRB report, there were nine for students, 15 for technical and administrative staff, four for academic staff, and two for governance. The 2015 GRB contained 19 indicators for students, 14 for technical and administrative staff, 19 for academic staff, and nine for governance. In addition, indicators focused on the distribution of women and men in a typical academic career at all levels (from students to full professors). Synthetic indexes (e.g., the glass-ceiling index) have also been implemented. The inclusion of these latter indicators was intended to compare UniFe with national data. The availability of national databases (e.g., MIUR database) supported comparative analyses so that the university could assess its performance on the light of the Italian one. GRB reports over time disclosed difficulties of UniFe in catching up with national evolution concerning the distribution of women and men in academic positions. More in depth, data reported a lower female representation at UniFe compared to the national average at all academic career levels (from researchers to full professors) and a lower capability to reduce the gender gap. Similarly, the glass ceiling index at UniFe is higher than the national average for all the years considered, suggesting increasing difficulties for women to reach higher positions in academia, in contrast with the national trend.

Since the 2013 GRB report, some indicators in line with the She Figures report (first the 2012 edition, then the 2015 edition) [24,38] have been added to support the context analysis and ensure benchmarking with national and international data. As stated in the 2013 GRB report: "The innovation introduced in the 2013 GRB allows a deeper analysis of the situation of the University of Ferrara in comparison to the Italian context and to the European average. For an immediate usability of the data, EU flags were inserted to identify indicators which can also be found in the She Figures, with the indication of the page and table or figure numbers referring to the 2012 She Figures Report" (2013 GRB report, p. 13).

The She Figures reports focus narrowly on researchers in HEIs, and therefore their indicators mainly pertain to academic staff, and to students engaged in research activities 
(i.e., $\mathrm{PhD}$ students). This allowed UniFe to compare its own context to both national and international data, although at the country level, and to align data analysis with European categories concerning fields of research and development and fields of education and training. These analyses prompted further investigation of vertical and horizontal segregation patterns. For instance, data on age distribution regarding careers levels underscored how men reach higher positions at younger ages than women do. Moreover, indicators show the proportion of female academics in the different career levels and emphasize UniFe's aforementioned delay in bridging the gender gap, compared to the Italian context.

Context analysis also highlighted relevant content in the 2017 GRB report. Following the three-year structure in GRB reporting that had been established in 2016, the 2017 GRB report supported the 2017-2019 PAP's objectives with a context analysis aimed at detecting gender differences and needs. The latter context analysis presented a situation that is quite similar to the one of the first GRB report. This is attributed to the slowness of cultural change and of the impact of the positive actions aimed at GE that were implemented over time. However, the increasing number of indicators included in the context analysis gave a more critical assessment of the situation and helped in defining more specific GE objectives in strategic documents. In keeping with this structure of publication, context analysis was absent from the 2016 and 2018 GRB reports.

\subsection{Positive Action Plan}

The PAP description was included in the GRB reports for the 2011-2017 period. In the first two publications, the PAP was mentioned, and its objectives and lines of actions briefly reported, but these initial reports did not contain an in-depth analysis of the PAP's content. The PAP's 2011-2013 objectives were threefold. The first objective referred to supporting information and education concerning GE: The plan suggested consistent positive actions to disseminate the EC and SGC's activities, raise awareness at UniFe on GE issues, and collaborate with other institutions in organizing meetings and conferences on GE. The second objective referred to producing gender statistics: here the plan suggested specific actions to produce the GRB report and to collect gender data. Further, positive actions aimed to monitor recruiting processes for academics as well as technical and administrative staff, with a focus on appointments committees' gender composition. The third objective aimed to promote employees' work-life balance through actions such as teleworking initiatives and agreeing on discounted fees for summer camps, kindergartens, and schools for students and employees with children.

Since the 2013 GRB report, a specific chapter has been devoted to the PAP. Besides the PAP's 2011-2013 objectives, the 2013 GRB report also states that all the planned objectives had been achieved; however, although it describes positive actions (see Section 4.3) it gives little evidence in the specific chapter to support the claim. The context analysis presented in the 2011-2013 GRB reports supported the need for action to incentivize female participation in governance, to rebalance gender distribution of academics, and to encourage technical and administrative staff's work-life balance. The chapter also contains a brief description of the 2014-2016 PAP's objectives and discusses PAP's inclusion in the Strategic Plan, as well as GRB's role as a tool to monitor GE policies (because the report was published in late 2014). These points are also mentioned in the 2014 GRB report. GE objectives in this PAP integrated the 2011-2013 ones. Supporting information and education on GE and promoting work-life balance were still included with quite similar positive actions. Concerning the first objective, a new action foresaw the creation of guidelines for gender inclusive language in administrative documents. An additional objective in the PAP concerned the dissemination on GE practices by creating a webpage with information about the activities promoted by the Rector's Deputy for Equal Opportunities, the EC and the SGC. Following the results of the context analysis, the PAP also aimed to promote the equal representation of women and men in governance bodies. In this regard, positive actions consisted of getting a clause in the university Statute approved to guarantee balanced gender representation in academic bodies, and specifically monitoring election 
processes in terms of the number and gender of candidates. Last, the GRB process and GRB report were linked to the objective of supporting GE through promoting projects for equal opportunities. The GRB report has become a structured practice at UniFe, and the 2014-2016 PAP designated GRB as a tool to also monitor the positive actions. Here, GRB was considered transversal to all the PAP's goals and functional in defining university strategies consistent with the GRB process' aims.

In the 2015 GRB report, the chapter devoted to the 2014-2016 PAP is not limited to describing the plan's objectives but involves various kinds of content: It lists the PAP's objectives and provides a chart showing all the positive actions connected to the objectives. In a separate paragraph, the chapter also describes these actions in greater depth and supports its description with results analyses.

Conversely, the structure of the 2016 GRB report is consistent with the 2014 GRB report and previous ones where a specific chapter had been dedicated to PAP objectives: In this particular report, the 2014-2016 PAP goals are reported, and the link with the Strategic Plan and the Performance Plan is noted. The report, which was published in 2017, also mentions the contents of the 2017-2019 PAP and its link to UniFe strategy. A chart summarizes the new PAP objectives and lists all the related actions. Although limited to the 2017-2019 PAP, the same information can be found in the 2017 GRB report. The 2017-2019 PAP expanded the number of positive actions for previous GE objectives and presented additional goals. Actions for supporting information and education on GE included courses (i.e., summer schools) on equal opportunities and the development of an optional and transdisciplinary course on GE for master's students. The objective of promoting work-life balance was integrated with actions introducing higher flexibility in technical and administrative staff's working hours. Disseminating GE practices through a specific webpage and drafting guidelines for gender inclusive language, were maintained. Concerning the aim of promoting the equal representation of women and men in governance bodies, positive actions aimed to monitor the composition of governance bodies that would ensure respect for balanced gender representation (consistent with the 2014-2016 PAP). These bodies would also monitor the normative obligation to justify selecting a particular candidate in recruiting processes if candidates have equal qualifications. Further, they would monitor the normative obligation to reserve at least one third of the members of the appointment's committees to the less represented gender, and they would reduce teaching loads for academics in institutional positions. The objective of supporting GE through promoting projects for equal opportunities was integrated by suggesting different specific actions such as activating research projects on the topic. In addition, the PAP emphasized the need to exploit GRB potentialities by fully integrating the gender approach in the budgeting process.

The 2018 GRB report does not describe the PAP. In line with this publication's aims, which will be detailed in Section 4.6, the discussion about the PAP is limited to the plan's development process and integration with GRB.

\subsection{Description of Positive Actions}

Consistent with reporting about PAP objectives, specific sections in the 2011-2017 GRB reports describe the positive actions implemented at UniFe. However, the characteristics of such sections have changed over time.

In the first few reports, these sections consisted of a brief description of the actions put in place during the year with little reference to specific objectives in the PAP. In the 2011 GRB report, in particular, the description of positive actions also included an objective description, which made it a challenge to understand how the actions may have helped to reach the goals. In the one GRB report of 2012, after the description of the positive actions, a table listed the objectives and the consistent actions, synthetizing the activities performed during the year. This improved comprehension of the relationship between the PAP's objectives and the positive actions. However, the description of the actions performed 
was not accompanied by an actual assessment of their results, and the report's concluding comments give no reflection on achieving GE objectives.

Since the 2014-2016 PAP, UniFe has refined the plan by stating the objectives more clearly and identifying the actions relating to them. Therefore, since the 2014 GRB report, the GRB reports have accounted for the positive actions implemented during the year and now clearly state how every action contributes to the related goals. However, until the 2015 GRB report, when the results of the positive actions were assessed with the help of specific indicators (discussed below in Section 4.4), the description of positive actions was limited to narratives reporting the activities carried out during the year.

The 2016 GRB report, which takes stock of the 2014-2016 PAP, describes the activities performed in the three-year period more broadly. Therefore, in this report, more details are provided about the positive actions' evolution over time, as well as the actors and the external institutions involved. The 2017 GRB report describes the positive actions with a narrow focus on 2017 (the first year of the 2017-2019 PAP), while the 2018 GRB report does not mention any information about positive actions.

\subsection{Assessment of Positive Actions}

The first time the GRB reports contained specific results indicators for positive actions was in the 2015 version. Because their main focus was context analysis, the 2011-2014 GRB reports did not provide information about the results of the positive actions. After designating GRB as a monitoring tool in 2014, UniFe started developing indicators to measure the results of its positive actions: "The analysis aims at verifying the correspondence between what was planned during the three-year planning and the results obtained" (2016 GRB report, p. 11).

In the 2015-2017 GRB reports, the descriptions of positive actions appeared along with specific measures supporting, where data was available, the assessment of the positive actions that had been implemented. Graphs and tables depicted the various data points, including: participation in activities, participation rates compared with the total population/invited participants, participant satisfaction, and the gender composition of those who were involved in the actions and of the main beneficiaries. In the 2015 GRB report, indicators are included in the same chapter that describes the positive actions and mainly refer only to the year under investigation (or, on occasion, to the previous years if the positive actions were consistent with those implemented in the previous PAP).

Conversely, and in line with its aims to assess the 2014-2016 PAP, the 2016 GRB report adopted a broader perspective by focusing on all three years and including a chapter dedicated to the topic for the first time. Further, in the 2017 GRB report, the chapter on the assessment of positive actions focused more on the recent actions introduced as part of the 2017-2019 PAP; however, it also accounted for previous years by referring to positive actions that both the 2014-2016 and 2017-2019 PAPs considered. Notably, the 2017 GRB report accounts for the first year of the 2017-2019 PAP. At the time of the analysis some of the positive actions included in the PAP had not started yet. For instance, the action addressing the work-life balance objective and related to the flexibility of technical and administrative staffs' working hours was only at a preliminary stage, so the report includes only a description of the agreements between UniFe and trade unions.

The consistency of PAPs' objectives and positive actions between the 2011-2013 and 2017-2019 PAPs allowed to analyze their results over time, as several indicators had remained the same. For example, concerning the aim of supporting information and education on GE issues, the 2015 data reported higher female participation in education activities on GE and limited participation of both male and female students from STEM fields. In the following year, results confirmed the trend regarding the predominance of female students in GE-aligned courses. However, the results also reported an increased interest in the topic. From 2015 to 2016 the numbers of students enrolled in these courses increased by one third and the number of men almost doubled. Only a few students in the STEM fields attended. In 2017, the number of enrolled students slightly decreased 
but the proportion of male participants increased. Further, the numbers of those who dropped out progressively decreased. The data suggested the need for reflection on mens' awareness of GE issues, and on the scientific fields and kinds of reasoning that could enhance participation in such courses and commitment to complete those.

Concerning work-life balance, the report presented the distribution of teleworking positions by gender for the period 2013-2017. The increasing requests during the whole period, especially women's requests, suggested a growing need for female employees to balance working activity with private life, due to family burdens that tend predominantly to put women at a disadvantage. In response, in 2016 UniFe decided to remove a cap on teleworking positions, accommodating all such requests.

Positive action' assessment in 2015-2017 GRB reports further referred to the election processes' monitoring activity. The clause in the university Statute provides an extension of the deadline for nominations if the gender balance requirement among candidates is not satisfied. The results suggest that the action, at least in the three years considered, did not have the desired effect. In fact, none of the cases in which the extension of the deadline was necessary generated applications that allowed a balance in gender disparity. This led to reflections on cultural or other types of obstacles for candidatures.

The 2017 GRB report also accounted for the two actions included in the 2017-2019 PAP: monitoring the obligation to justify the selection of a candidate in recruiting processes when candidates have equal qualifications, and respecting the equality principle in how they compose the appointments committees. Regarding the first action, monitoring candidate selection did not produce any cases. It emerged that almost half of the committees selecting candidates for research fellowships and researchers' positions did not satisfy the requirements, so the gender representation was not balanced. In contrast, the entirety of the committees for technical and administrative staff honored the normative obligation. No committees concerning full and associate professors were reported.

While the reports aim to assess actions' results and impact (as stated in the reports' introductions), positive actions' assessment in GRB reports is limited to the results of the actions, as the examples demonstrate. The reports did not identify the impact indicators that could assist in evaluating GE objectives achievement. Further, the 2018 GRB report contains no assessment of positive actions. Because of its aim to investigate GRB's integration with the strategic cycle, the report explicitly does not provide information on the PAP objectives, a description of positive actions, or any results.

\subsection{Budget Analysis}

The budget analysis was included in GRB to support the evaluation of expenses to combat gender inequality. However, the analyses were limited to the budget for positive actions and the budget for equal opportunities (i.e., estimated expenses to meet the PAP objectives).

The budget for positive actions was first included in the 2015 GRB report, when UniFe started assessing the results of its positive actions. This assessment was supported by a comparative analysis of the estimated expenses in the budget plan and the actual expenses for each action. The budgets for positive actions consider estimated expenses for each year, which are then compared with the expenses for the specific year. For this analysis, the 2015-2017 GRB reports adopted an approach similar to the one reported for the assessment of positive actions: They refer only to the specific reporting year (or, occasionally, to previous years, depending on the consistency of the positive actions over time and the reports' aims). For example, the work-life balance objective included a positive action directed at supporting kindergarten enrollments for children of students and employees, through discounted tuition fees. UniFe provided support proportional to the family income. The 2015-2017 GRB reports present the data concerning estimated and actual expenses for the action from 2014 to 2016. The estimated amounts were never exceeded, and the number of requests remained constant between 2014 and 2015, while it decreased in 2016. However, in 2015 and 2016 the cost per capita was more than double that of 2014. This 
suggested that the average income of the actions' beneficiaries decreased over time and that individuals most in need, had accessed the facility.

The 2016 and 2017 GRB reports included an analysis of the equal opportunity budget. The analysis refers only to estimated expenses over a three-year period and is based on the timing of the budget approval by the Board of Directors. For example, in the 2016 GRB report, the budget analysis refers to the 2015, 2016, and 2017 budgets, which are the budgets that were approved between 2014 and 2016; in the 2017 GRB report, the budgets refer to 2016, 2017 and 2018.

The analysis of the equal opportunity budget compares the different amounts of estimated expenditure over three years. Calculations are also provided by type of expenditure (e.g., equipment, assistance, facilities, grants, etc.) over the three-year period, and the share of each type of expense is shown to support the evaluation of priorities in the budget definition. The equal opportunity budget increased in the period 2015-2017, while it strongly decreased in 2018, when the overall budget was reduced by one-fifth compared the 2015 one. Until 2017, the estimated equal opportunity budget was allocated largely to positive actions for increasing employees' well-being (ranging between $67 \%$ and $52 \%$ of the budget). This amount was drastically reduced in 2018 (to $17 \%$ of the budget), when major emphasis was on providing research grants (absent in the previous years), scholarships, and prizes, as well as to services and facilities for students and scholarship holders (together accounting for $65 \%$ of the budget). However, there is no comparison between estimated and actual expenditures. Therefore, the GRB reports do not provide and analyze the actual attention UniFe paid to equal opportunities.

The equal opportunity budget is also measured against the overall budget to evaluate how much attention went to GE and the university's awareness of this issue, although again, it was limited to estimated expenditure. The incidence of equal opportunities on the total budget is less than $0.01 \%$ for all the years considered (with a minimum value of $0.051 \%$ in 2018). Lastly, the report focuses narrowly on estimated expenses regarding assets in the equal opportunity budget, which are compared with the total budget for assets at UniFe to explore the trend of supporting investments that can produce equal opportunities and positive actions. In this case, the incidence of equal opportunities investments on the total amount of investments is $0.6 \%$ on average in the period considered.

\subsection{Integration with Strategy}

The integration with strategy is addressed in multiple GRB reports, albeit to different degrees. The first reference to the actual involvement of GRB in the strategic process is presented in the 2013 GRB report, which anticipates the interplay between the 2014-2016 PAP and both the 2014-2016 Strategic Plan and the 2014-2016 Performance Plan: "Respecting the imperative of gender mainstreaming, the University's 2014-2016 PAP was also integrated into the 2014-2016 three-year Strategic Plan and the 2014-2016 Performance Plan. The articulation of the actions into eight thematic areas facilitates their reading and will allow, in the future, a better comparison of best practices" (2013 GRB report, p. 69).

As noted in the 2014 and 2015 GRB reports, the PAP objectives were included in the strategic documents in a section on equal opportunities (strategic area no. 4 "Strengthening of services and interventions in favor of personnel and equal opportunities"). The section also listed consistent actions and targets that explicitly referred to the PAP.

Since the publication of the 2015 GRB report in late 2016, the reports have increased the integration between the 2017-2019 PAP and strategic documents, although limited to the Strategic Plan and the Performance Plan. As previously seen, these documents included the PAP in full, and its objectives are again covered by a specific section of the 2017-2019 Strategic Plan, as well as the 2017-2019 Performance Plan (strategic area no. 9 "Equality, equal opportunities and well-being for those who study and work at UniFe"). The 2016 and 2017 GRB reports merely noted the inclusion of the PAP in such documents.

Based on the triennial reporting of GRB, the 2018 GRB report focused entirely on the full exploitation of GRB potentialities in terms of its integration with UniFe's strategy. In 
this regard, the 2018 GRB report considered the overall planning and reporting processes and discussed GE in strategy. Having been developed in late 2019, the report also explored the extent to which GRB at UniFe had adopted the suggestions from the national guidelines published by the ANVUR and the CRUI and focused on the integration of GRB with the performance cycle and the strategic implementation of GRB at HEIs [20,21].

"The aim [of the report] is to understand how GRB, and, in particular, the context analysis and the result analysis, can contribute to the definition of University policies that take into account their direct or indirect effects in terms of GE, with a view to implementing a gender mainstreaming strategy. In this sense, it is useful to understand how GRB can relate to the main planning and reporting documents drawn up by the University, in order to ensure the conscious integration of the gender dimension in the creation of all these documents" (2018 GRB report, p. 14). The 2018 GRB report had three aims: (i) to assess the state of effective integration of the gender perspective in the planning and reporting documents; (ii) to identify suggestions that would help better (and completely) integrate the gender perspective into these documents; and (iii) to describe how GRB can be properly integrated into strategic documents.

The documents that were analyzed include the PAP, the Strategic Plan, the Performance Plan, the annual and triennial budgets, and the Performance Report. Additional documents referred to planning staff and students' needs, such as the three-year Plan for Personnel Recruitment, the three-year Plan for Technical and Administrative Staff Training, and the Training Offer to Students. The three-year Corruption and Transparency Prevention Plan, the report of the University Assessment Unit, and the SGC Annual Report were also included in the analysis.

To meet its goals, the 2018 GRB report presented interviews with internal stakeholders, mainly the technical and administrative staff and those responsible for preparing the relevant documents. The report covered the characteristics of the documents, its approval and revision processes, its effects on the overall strategy, interviewees' opinions of the degree of integration of the GE perspective in the documents, and possible resistance to such integration as identified by the interviewees. An additional section assessed the actual integration of GRB and proposed how it could be integrated to exploit its full potential.

In its analysis, the 2018 GRB report provided evidence of the weak integration of GRB with the strategic cycle. In particular, the report highlights that the features of GRB are not known in-depth to the organization and that there is a shared but superficial knowledge of GRB and the content of the GRB reports within UniFe. Limits to the exploitation of the GRB's full potential were detected in the limited training the personnel had received on GE and GRB; the interviewees did not perceive the importance of promoting GE in the organization and sometimes resisted GE issues (or reported resistance when they discussed the documents' contents).

This shortcoming led to a low level of understanding regarding the potential of GRB at the organizational level. The integration of GE with strategy appears to be limited to specific sections in a few strategic documents (i.e., the Strategic Plan and the Performance Plan) that include PAP objectives. Moreover, no alignment with ANVUR and CRUI guidelines provisions was detected.

Further, one of the 2017-2019 Strategic Plan's stated goals was to reclassify expenditure to assess the congruence between GE objectives and budget allocation. However, the strategic documents contained no elements pertaining to the integration of GRB with the university budget through the recommended account-based approach (requiring the reclassification of expenses in a gender perspective). The 2018 GRB report revealed that UniFe had neglected to undertake a proper gender impact analysis of the year's expenditures.

The report concluded that the sectoral logics adopted did not support gender mainstreaming, which would have allowed the gender perspective to permeate all university policies. As for achieving the integration of a GE perspective, the 2018 GRB report emphasized the importance of training university personnel in GRB. The importance of more strictly aligning the timing of the GRB reports with the strategic cycle also emerged from the 
analysis. The report recommended a revision to planning and monitoring processes. It also called for an examination of the consistency of information needs during the development of strategic processes by using the information provided by context indicators and the assessment of positive actions. To have an impact on and inform the content of planning and reporting documents, this information should be available before the documents are drafted and discussed.

Table 3 synthetizes the contents of the GRB reports.

Table 3. Content of annual publications on GRB.

\begin{tabular}{|c|c|c|c|c|c|c|c|c|c|}
\hline & \multirow{2}{*}{ Content } & \multicolumn{8}{|c|}{ GRB Reports } \\
\hline & & 2011 & 2012 & 2013 & 2014 & 2015 & 2016 & 2017 & 2018 \\
\hline \multirow[t]{2}{*}{ Context analysis } & $\begin{array}{l}\text { Students, academic staff, technical and } \\
\text { administrative staff, and governance indicators }\end{array}$ & $\checkmark$ & $\checkmark$ & $\checkmark$ & $\checkmark$ & $\checkmark$ & & $\checkmark$ & \\
\hline & She Figures indicators & & & $\checkmark$ & $\checkmark$ & $\checkmark$ & & $\checkmark$ & \\
\hline Positive action plan & Positive action plan objectives & $\checkmark$ & $\checkmark$ & $\checkmark$ & $\checkmark$ & $\checkmark$ & $\checkmark$ & $\checkmark$ & \\
\hline Description of positive actions & Description of implemented positive actions & $\checkmark$ & $\checkmark$ & $\checkmark$ & $\checkmark$ & $\checkmark$ & $\checkmark$ & $\checkmark$ & \\
\hline Assessment of positive actions & Indicators of positive actions results & & & & & $\checkmark$ & $\checkmark$ & $\checkmark$ & \\
\hline \multirow{2}{*}{ Budget analysis } & Positive actions budget analysis & & & & & $\checkmark$ & $\checkmark$ & $\checkmark$ & \\
\hline & Analysis of equal opportunity budget & & & & & & $\checkmark$ & $\checkmark$ & \\
\hline Integration with strategy & Integration of GRB with strategic documents & & & & & & & & $\checkmark$ \\
\hline
\end{tabular}

\section{Discussion and Conclusions}

The current research contributes to exploring the patterns of GRB development at HEIs. The focus here is on UniFe, the first HEI in Italy to develop GRB and publish a GRB report. Therefore, the research aims are pursued through a content analysis of GRB reports. From this case, it emerges that GRB at the university has evolved but has not been fully integrated into the university's strategic policies. In particular, GRB has changed from being used for accountability purposes to serving as a performance measurement tool but without reaching its full potential. GRB was one of the 2011-2013 PAP's objectives related to producing gender statistics and having women involved at the decision-making level. The first GRB report was published as a separate chapter in the Social Report and the following year as a standalone document with context analyses relating to students, academic staff, technical and administrative staff, and governance. At that time, the role of GRB mainly pertained to accountability, in keeping with similar reports produced at the European level $[24,38]$. The information related to positive actions mainly consisted of descriptions, not assessment, and there was no evidence of any strategic integration of GE objectives.

With the implementation of the 2014-2016 PAP, which designated GRB as a permanent monitoring tool of GE policies and actions, GRB became a performance measurement instrument. In this respect, as already argued, GRB was used to monitor the results of positive actions and, subsequently, the expenses connected to those actions aimed at supporting decision making. Attempts had been made to increase the strategic relevance of GRB, but they appeared to be limited, which reduced GRB's potential to effect a change in society [13,25]. In 2016, the new UniFe Statute made the Board of Directors responsible for approving the GRB report. GE objectives were included in the university's Strategic Plan and the Performance Plan but were presented in a single, standalone chapter. A GE perspective was not included in the overall strategy. In addition, the gender impact analysis of expenditures through the gender budget, which had been anticipated in the 2017-2019 Strategic Plan, has not been implemented, which has prevented the GRB potentialities from being fully exploited. Since 2016, the aim of the three-year process in which different kinds of GRB content were investigated and reported has been to better support the integration of GRB with strategy, but with few results. This is in part due to the fact that UniFe has implemented a stand-alone 
management control process to assess the positive actions' effectiveness (and to allocate resources to the latter to support GE), which is parallel to the university's management control system. The construction of the GRB report is based on a protocol for data collection, which is defined by the scientific committee presiding over the university's GE strategy. The protocol provides a non-systematic and manual collection of information to support the GRB process, so it does not follow the university's traditional management control process. However, the data disclosed in the GRB reports are also functional to the GRB process. Then, the data on context analysis and actions' results is included in the traditional management control processes and is used for integrating a gender perspective in strategic documents. Despite GRB not being fully integrated in the strategic policies, it has triggered a process of cultural change with respect to gender issues, as over time, the GRB moved from a logic of mere reporting to one of measuring results through ad hoc control practices that can bolster the attribution of specific resources to GE objectives. These control practices were supported by the scientific committee coordinating with the working group responsible for data provision, to enhance the university's gender strategy.

In addition, the GRB process has seen the introduction of a series of result indicators which have allowed for better planning and monitoring activities. Some positive actions were indeed found to contribute to making gender issues more visible at the HEI: for instance, the regulation that would guarantee the less represented gender access to governance positions, and initiatives that would improve work-life balance for women were positive examples of actions that aimed to empower women and strengthen their presence in the university and in supporting cultural change toward GE. However, as it emerged from both context analyses and positive actions' assessment, the positive actions' contribution to the GE achievement was limited. The context analyses highlighted a constant trend of inequalities concerning horizontal and vertical segregation of female students, academics, and technical and administrative staff. Further, the role of women as caregivers continued to affect their presence in the workplace and the need for work-life balance. UniFe exhibited scarce capability in bridging the gender gap: The GE objectives included in the PAPs turned out to be consistent over time, as a consequence of the enduring gender issues emerging in the context.

Further, while assessing the positive actions, the university's focus remained on their results, although indicators of impact were not in place. Nevertheless, the long-term impact such initiatives had on GE requires analysis over a longer horizon as integrating gender in strategy started only in 2014 and, as the 2018 GRB reported, has not been fully accomplished yet.

The findings have also highlighted the need to conduct in-depth research within the university to reveal why GRB was so weakly integrated in the university strategy. The 2018 GRB report focused on these investigations but was limited to the technical and administrative staff in charge of preparing the drafts of strategic documents according to instructions from the governance bodies. The findings helped identify the factors hampering integration. Although the content of the GRB reports is well-known, some personnel have not been educated on GE accounting and do not fully perceive the value of such integration. Further, the misalignment of the GRB reports' publication times with those of strategic documents threatens integration, as the GRB reports do not provide the documents with consistent and up-to-date information when they are being drafted.

From this case, it emerges that GRB at UniFe has limitations as an accountability tool and a performance measurement instrument for decision making. GRB implementation at UniFe is consistent with what has been reported in literature with regard to the limited integration of GRB in budgeting practices [59], especially at local entities in Italy [64]. At UniFe, GRB has not developed according to the three main steps of context analysis, analysis of GE local practices, and gender impact analysis of expenditures [64]. While the first two steps have been taken at UniFe, the third is still underdeveloped and limited to being just a strategic aim. 
Following Steccolini [11], GRB at UniFe helps support the assessment of gender associated needs and contributes to a GE perspective on accountability while also presenting the challenges that reduce its potential. The publication of annual GRB reports following Rothe et al. [15] assisted the context analysis and the positive actions' assessment, while progress toward GE could be measured only in the long run. Therefore, the impact on GE results for the present remains unexplored. Further, linking the gender perspective to performance measurement is limited, since GRB as a practice consists of tools and instruments that can enhance decision making but without an interplay with strategy. In this regard, there is a notable absence of gender-responsive logics to guide strategy: GRB is not interwoven with the strategic cycle, which basically remains independent. Furthermore, the case presents the challenges to GRB implementation related to a low commitment to GE and scarce awareness of the importance of integration, as previously highlighted by literature [11]. Therefore, while the practices could boost the organization's awareness of GE issues inside the organization and promote communication with stakeholders and reporting on performance, there is a gap in how strategies are developed based on such practices $[53,54]$ and no gender impact analysis of expenditures, which affects how policies are defined [58]. Institutionalizing GRB, as the literature has recommended [11,59] has not been reached in this case. The fact that GRB is not integrated in the strategic cycle generates major risks, considering the role that GRB could take in promoting GE. This is especially unfortunate considering that GE represents a relevant target of the 2030 SDGs Agenda [7] and a necessary condition for achieving sustainability [6]. As the OECD [5] (p. 27) argues: "Past gender budgeting initiatives have often aimed at securing specific funding for targeted activities for women, as opposed to ensuring that resource allocation is based on full knowledge of how current policies and programs may impact women and men. Funding for targeted gender equality activities may be necessary but an ad hoc approach alone will not ensure that countries meet the goal of increased gender equality across sectors. Indeed, such an approach risks leading to a marginalization of efforts and weaker overall impact. Initiatives which focus only on adding resources for targeted activities for women risk resulting in 'separate budgets' or being carried out in isolation from the regular budget and policy-development processes." Therefore, from the case, it emerged that GRB cannot reach its full potential, especially regarding the GE agenda mentioned in the UN SDGs, to act as an agent of change for sustainability [13].

Given the key role women could play in meeting the SDG agenda's targets by achieving GE [8], the development of GRB is highly recommended to address persisting gender disparities. As various scholars have argued, GRB can provide public institutions with a valuable approach to test the effectiveness of policies they designed and can promote corrections to support GE $[9,10]$. To ensure this change is transformative in universities and in reaching sustainable GE, a GRB culture permeating the university and incorporating the gender perspective in its management control system are necessary conditions [15]. If the GRB does not meet these conditions, GRB risks remaining an episodic exercise that in the long term will not contribute to GE. This paper has discussed the GRB's potential by taking a step back from the gender neutrality of performance measurement systems and public budgets [27,48]. It contributes to the debate around the characteristics of GRB in the public sector with a specific focus on academia as a field requiring further study [45]. The research also contributes to investigating the actual capacity of GRB to affect strategic policies [60] and its integration in HEIs' budgeting process [48]. Although the GRB report could support management control processes, due to poor integration in the university strategy its contribution to analyzing the impact of budgeting decisions on women and men, and to enhancing management toward GE [15,42] is lacking.

The findings of the investigation, which sought the reasons for the limited strategic relevance of GRB, make it possible to identify managerial implications for HEIs. First, it is necessary to give the staff involved in the preparation of strategic documents proper training in GE accounting and explain the processes of GRB's integration with university strategy, as well as the advantages related to this, and reduce resistance. Second, it is 
important to align the publication of GRB reports with the strategic documents and to incentivize the adoption of GE data for strategic purposes.

The case then traces a reflection on HEIs' readiness to implement GRB and the need to support this path by developing awareness of the topic. The recent Directive 2/2019 [18] and especially the guidelines by the ANVUR and the CRUI $[20,21]$ might spur a shared discussion among HEIs about the meaning of GRB, how to make institutions less isolated, and how to support a common direction for both those institutions that have started implementing GRB, as well as those that have not done so yet.

This case also presents the limits that are inherent in the methodology. Further research is needed to explore the development of GRB in HEIs from a broader perspective. For instance, studies at the national level might investigate the different approaches to GRB. Comparative case studies could also support the discussion of the internal and external factors that can enhance or inhibit GRB practices and logics. Lastly, future studies should explore whether HEIs have revised their GRB according to the aforementioned guidelines.

Author Contributions: Conceptualization, C.O., C.C. and E.V.; methodology, C.O. and C.C.; validation, E.V.; formal analysis, C.O. and C.C.; investigation, C.O. and C.C.; writing-original draft preparation, C.O., C.C. and E.V.; writing-review and editing, C.O., C.C. and E.V.; supervision, E.V. All authors have read and agreed to the published version of the manuscript.

Funding: This research received no external funding.

Institutional Review Board Statement: Not applicable.

Informed Consent Statement: Not applicable.

Data Availability Statement: No new data were created or analyzed in this study.

Conflicts of Interest: The authors declare no conflict of interest.

\section{References}

1. Alonso-Almeida, M.D.M.; Llach, J.; Marimon, F. A closer look at the 'Global Reporting Initiative' sustainability reporting as a tool to implement environmental and social policies: A worldwide sector analysis. Corp. Soc. Responsib. Environ. Manag. 2014, 21, 318-335. [CrossRef]

2. Salzmann, O.; Ionescu-Somers, A.; Steger, U. The business case for corporate sustainability: Literature review and research options. Eur. Manag. J. 2005, 23, 27-36. [CrossRef]

3. Hopper, T. Stop accounting myopia:-Think globally: A polemic. J. Account. Organ. Chang. 2019, 15, 87-99. [CrossRef]

4. Ioannides, I. EU Gender Action Plan 2016-2020 at Year One: European Implementation Assessment; European Parliamentary Research Service: Brussels, Belgium, 2017. Available online: https://op.europa.eu/en/publication-detail/-/publication/62f7aa16-c438-1 1e7-9b01-01aa75ed71a1 (accessed on 11 November 2020).

5. Downes, R.; von Trapp, L.; Nicol, S. Gender budgeting in OECD countries. OECD J. Budg. 2017, 16, 71-107. Available online: http:/ / www.oecd.org/gender/Gender-Budgeting-in-OECD-countries.pdf (accessed on 11 November 2020).

6. Botlhale, E. Gender-responsive budgeting: The case for Botswana. Dev. South. Afr. 2011, 28, 61-74. [CrossRef]

7. Razavi, S. The 2030 Agenda: Challenges of implementation to attain gender equality and women's rights. Gend. Dev. 2016, 24, 25-41. [CrossRef]

8. Stevens, C. Are women the key to sustainable development. Sustain. Dev. Insights 2010, 3, 1-8.

9. Odera, J.A.; Mulusa, J. SDGs, Gender Equality and Women's Empowerment: What Prospects for Delivery? In Sustainable Development Goals and Human Rights. Interdisciplinary Studies in Human Rights; Kaltenborn, M., Krajewski, M., Kuhn, H., Eds.; Springer: Cham, Switzerland, 2020; Volume 5, pp. 95-118. [CrossRef]

10. Galizzi, G.; Bassani, G.; Cattaneo, C. Adoption of Gender-Responsive Budgeting (GRB) by an Italian Municipality. Adm. Sci. 2018, 8, 68. [CrossRef]

11. Steccolini, I. New development: Gender (responsive) budgeting-A reflection on critical issues and future challenges. Public Money Manag. 2019, 39, 379-383. [CrossRef]

12. Maas, K.; Schaltegger, S.; Crutzen, N. Integrating corporate sustainability assessment, management accounting, control, and reporting. J. Clean. Prod. 2016, 136, 237-248. [CrossRef]

13. Ceulemans, K.; Lozano, R.; Alonso-Almeida, M.D.M. Sustainability reporting in higher education: Interconnecting the reporting process and organisational change management for sustainability. Sustainability 2015, 7, 8881-8903. [CrossRef]

14. Brusca, I.; Labrador, M.; Larran, M. The challenge of sustainability and integrated reporting at universities: A case study. J. Clean. Prod. 2018, 188, 347-354. [CrossRef] 
15. Rothe, A.; Erbe, B.; Fröhlich, W.; Klatzer, E.; Lapniewska, Z.; Mayrhofer, M.; Neumayr, M.; Pichlbauer, M.; Tarasiewicz, M.; Zebisch, J.; et al. Gender Budgeting As A Management Strategy for Gender Equality at Universities; Frauenakademie München e.V. München: Munich, Germany, 2008.

16. Vagnoni, E.; Fioravanti, C.; Oppi, C.; Cavicchi, C. Gender diversity and governance: An explorative study of Italian universities. In Proceedings of the Seminar La Pari Rappresentazione Negli Organi di Ateneo, Teoria e prassi a Confronto, University of Ferrara, Ferrara, Italy, 17 October 2014.

17. Italian Parliament. Legislative Decree 150/2009. Attuazione della Legge 4 Marzo 2009, n. 15, in Materia di Ottimizzazione della Produttività del Lavoro Pubblico e di Efficienza e Trasparenza delle Pubbliche Amministrazioni. 2009. Available online: https: / / www.camera.it/parlam/leggi/deleghe/09150dl.htm (accessed on 16 November 2020).

18. Ministry of Public Administration. Directive 2/2019; Misure per Promuovere le Pari Opportunità e Rafforzare il Ruolo dei Comitati Unici di Garanzia Nelle Amministrazioni Pubbliche. 2019. Available online: http:/ /www.funzionepubblica.gov.it/ articolo/dipartimento/27-06-2019/direttiva-recante-\%E2\%80\%9Cmisure-promuovere-le-pari-opportunita-e (accessed on 16 November 2020).

19. Addis, E.; Biasini, C.; Calloni, M.; Loretoni, A.; Mancini, M.; Serughetti, G. Indicazioni per Azioni Positive del MIUR Sui Temi di Genere Nell'Università e Nella Ricerca. 2018. Available online: https:/ /www.miur.gov.it/documents/20182/991467 /Documento_+Indicazioni_azioni_positive_MIUR_su_temi_genere.pdf/23e81cb6-f15a-4249-9bd6-cf4fdcd113a8?version=1.0 (accessed on 16 November 2020).

20. ANVUR. Linee Guida per la Gestione Integrata dei Cicli di Performance e di Bilancio delle Università Statali Italiane. 2019. Available online: https:/ / www.anvur.it/wp-content/uploads/2019/01/Linee-Guida-per-la-gestione-integrata-del-ciclo-dellaperformance-e-del-bilancio.pdf (accessed on 16 November 2020).

21. CRUI. Linee Guida Per Il Bilancio di Genere Negli Atenei Italiani; 2019. Available online: https:/ /www2.crui.it/crui/Linee_Guida_ Bilancio_di_Genere_negli_Atenei_italiani.pdf (accessed on 16 November 2020).

22. Nowotny, H.; Scott, P.; Gibbons, M. Re-Thinking Science. Knowledge and the Public in an Age of Uncertainty; Polity Press: Cambridge, UK, 2001.

23. Prages. Guidelines for Gender Equality Programmes in Science. 2009. Available online: https://ec.europa.eu/research/swafs/ pdf/pub_gender_equality/prages-guidelines_en.pdf (accessed on 16 November 2020).

24. European Commission. She Figures 2012. 2012. Available online: http:/ / ec.europa.eu/research/science-society/document library/pdf_06/she-figures-2012_en.pdf (accessed on 16 November 2020).

25. Galizzi, G.; Siboni, B. Positive action plans in Italian universities: Does gender really matter? Meditari Account. Res. 2016, 24, 246-268. [CrossRef]

26. Debski, M.; Erbe, B.; Fröhlich, W.; Klatzer, E.; Lapniewska, Z.; Mayrhofer, M.; Neumayr, M.; Pichlbauer, M.; Rothe, A.; Tarasiewicz, M.; et al. Development of Instruments for Gender Budgeting at Universities; Frauenakademie München e.V. München: Munich, Germany, 2007.

27. Parker, L.D. Strategic management and accounting processes: Acknowledging gender. Account. Audit. Account. J. 2008, 21, 611-631. [CrossRef]

28. Walker, S. Accounting histories of women: Beyond recovery? Account. Audit. Account. J. 2008, 21, 580-610. [CrossRef]

29. Whiting, R.H.; Gammie, E.; Herbohn, K. Women and the prospects for partnership in professional accountancy firms. Acc. Fin. 2014, 55, 575-605. [CrossRef]

30. Gallhofer, S.; Haslam, J.; Kamla, R. The accountancy profession and the ambiguities of globalisation in a post-colonial, Middle Eastern and Islamic context: Perceptions of accountants in Syria. Crit. Perspect. Account. 2011, 22, 376-395. [CrossRef]

31. Haynes, K. (Re)figuring accounting and maternal bodies: The gendered embodiment of accounting professionals. Account. Org. Soc. 2008, 33, 328-348. [CrossRef]

32. Broadbent, J.; Kirkham, L. Glass ceiling, glass cliffs or new worlds? Revisiting gender and accounting. Account. Audit. Account. J. 2008, 21, 456-473. [CrossRef]

33. Komori, N. Toward the feminization of accounting practice: Lessons from the experiences of Japanese women in the accounting profession. Account. Audit. Account. J. 2008, 21, 507-538. [CrossRef]

34. Wessels, P.L.; Steenkamp, L.P. An investigation into students' perceptions of accountants. Meditari Account. Res. 2009, 17, 117-132. [CrossRef]

35. Dambrin, C.; Lambert, C. Who is she and who are we? A reflexive journey in research into the rarity of women in the highest ranks of accountancy. Crit. Perspect. Account. 2012, 23, 1-16. [CrossRef]

36. Baldarelli, M.G.; Del Baldo, M.; Vignini, S. Pink accounting in Italy: Cultural perspectives over discrimination and/or lack of interest. Meditari Account. Res. 2016, 24, 269-292. [CrossRef]

37. Van den Brink, M.; Benschop, Y. Gender practices in the construction of academic excellence: Sheep with five legs. Organization 2011, 19, 507-524. [CrossRef]

38. European Commission. She Figures 2015. 2015. Available online: https://ec.europa.eu/research/swafs/pdf/pub_gender_ equality /she_figures_2015-final.pdf (accessed on 19 November 2020).

39. European Commission. She Figures 2018. 2018. Available online: https://ec.europa.eu/info/publications/she-figures-2018_en (accessed on 19 November 2020). 
40. Butler, N.; Spoelstra, S. The regime of excellence and the erosion of ethos in critical management studies. Br. J. Manag. 2014, 25, 538-550. [CrossRef]

41. Heijstra, T.M.; Steinpórsdóttir, F.S.; Einarsdóttir, T. Academic career making and the double-edged role of academic housework. Gend Educ. 2017, 29, 764-780. [CrossRef]

42. Steinpórsdóttir, F.S.; Heijstra, T.M.; Einarsdóttir, T. The Making of the ‘Excellent' University: A Drawback for Gender Equality. Ephemera Theor. Polit. Org. 2017, 17, 557-582.

43. Broadbent, J. A gender agenda. Meditari Account. Res. 2016, 24, 169-181. [CrossRef]

44. Siboni, B.; Sangiorgi, D.; Farneti, F.; De Villiers, C. Gender (in) accounting: Insights, gaps and an agenda for future research. Meditari Account. Res. 2016, 24, 158-168. [CrossRef]

45. Timmers, T.M.; Willemsen, T.M.; Tijdens, K.G. Gender diversity policies in universities: A multi-perspective framework of policy measures. High. Educ. 2010, 59, 719-735. [CrossRef]

46. Syna, H.D.; Costea, C.E. Gender Effects in Top Management. In Women's Voices in Management; Palgrave Macmillan: London, UK, 2015; pp. 3-11.

47. Elson, D. Gender Budget Initiative: Background Papers; Commonwealth Secretariat: London, UK, 1999.

48. Rubin, M.M.; Bartle, J.R. Integrating gender into government budgets: A new perspective. Public Adm Rev. 2005, 65, 259-272. [CrossRef]

49. Addabbo, T.; Gunluk-Senesen, G.; O'Hagan, A. Gender budgeting: Insights from current methodologies and experiences in Europe. Politica Econ. 2015, 31, 125-134. [CrossRef]

50. Sharp, R.; Broomhill, R. Budgeting for equality: The Australian experience. Fem Econ. 2002, 8, 25-47. [CrossRef]

51. O'Hagan, A. Conceptual and institutional origins of gender budgeting. In Gender Budgeting in Europe; O'Hagan, A., Klatzer, E., Eds.; Palgrave Macmillan: Cham, Switzerland, 2018; pp. 19-42.

52. Sarraf, F. Gender-responsive government budgeting. In IMF Working Paper No. 03/83; 2003. Available online: https: / / www.elibrary.imf.org/doc/IMF001/02722-9781451850567/02722-9781451850567/Other_formats/Source_PDF/02722-9781 451896732.pdf?redirect=true (accessed on 23 November 2020).

53. Sharp, R. Moving Forward: Multiple Strategies and Guiding Goals. In Gender Budget Initiatives: Strategies, Concepts and Experiences; Klot, J., Holvoet, N., Villagomez, E., Judd, K., Eds.; United Nations Development Fund for Women: New York, NY, USA, 2002; pp. 86-98.

54. Balmori, H.H. Gender and Budgets: Overview Report; BRIDGE Development-Gender, Institute of Development Studies: Brighton, UK, 2003; in press. Available online: https://doc.rero.ch/record/256064/files/01-IDS_Bridge_Budgets_EN.pdf (accessed on 23 November 2020).

55. Lukman, R.; Glavič, P. What are the key elements of a sustainable university? Clean Technol. Environ. Policy 2007, 9, 103-114. [CrossRef]

56. Steccolini, I. L'accountability delle pubbliche amministrazioni. Definizione, profili di classificazione, evoluzione. In L'accountability Delle Amministrazioni Pubbliche; Pezzani, F., Ed.; Egea: Milan, Italy, 2003; pp. 17-32.

57. Holvoet, N. Gender budgeting in Belgium: Findings from a pilot project. Eur. Soc. 2007, 9, 275-300. [CrossRef]

58. Miles, K. Embedding gender in sustainability report. Sustain. Account. Manag. Policy J. 2011, 2, 139-146. [CrossRef]

59. Khalifa, R.; Scarparo, S. Gender Responsive Budgeting: A tool for gender equality. Crit. Perspect. Account. 2020, in press. [CrossRef]

60. Marx, U. Accounting for equality: Gender budgeting and moderate feminism. Gend. Work Organ. 2019, 26, 1176-1190. [CrossRef]

61. Steinpórsdóttir, F.S.; Heijstra, T.M.; Einarsdóttir, P.J.; Pétursdóttir, G.M. Gender Budgeting in Academia-Toolkit, GARCIA Working Paper n. 14.; University of Trento: Trento, Italy, 2016. Available online: http://garciaproject.eu/wp-content/uploads/2016/12/ GARCIA_D5.3-Gender-budgeting-in-academia-toolkit.pdf (accessed on 23 November 2020).

62. Özbilgin, M.F. From journal rankings to making sense of the world. Acad. Manag. Learn. Educ. 2009, 8, 113-121. [CrossRef]

63. Del Gesso, C. Gender Budgeting Implementation in Italian Regional Governments: Institutional Behavior for Gender Equality and Women's Empowerment. Int. Bus. Res. 2019, 12, 110-124. [CrossRef]

64. Bettio, F.; Rosselli, A. Gender Budgeting in Italy: A Laboratory for Alternative Methodologies? In Gender Budgeting in Europe; O'Hagan, A., Klatzer, E., Eds.; Palgrave Macmillan: Cham, Switzerland, 2018; pp. 199-220.

65. Mazzotta, R.; Nardo, M.T.; Pastore, P.; Vingelli, G. Board composition and gender sensitivity approach in Italian universities. Meditari Acc. Res. 2020, 28, 1013-1036. [CrossRef]

66. Italian Parliament. Legislative Decree 198/2006. Codice delle Pari Opportunità Tra Uomo e Donna, a Norma Dell'Articolo 6 della Legge 28 Novembre 2005, n. 246. 2006. Available online: https://www.camera.it/parlam/leggi/deleghe/testi/06198dl.htm\#: \{\}: text=4\%2C\%20comma\%203)- ,1.,i\%20livelli\%20della\%20gerarchia\%20professionale. (accessed on 28 November 2020).

67. Ministry of Public Administration. Directive 23 May 2007; Misure per Attuare Pari Opportunità tra Uomini e Donne Nelle Amministrazioni Pubbliche. 2007. Available online: https://www.gazzettaufficiale.it/eli/id/2007/07/27/07A06830/sg (accessed on 28 November 2020).

68. Ministry of Education, University and Research. Portale dei Dati Dell'Istruzione Superiore. Available online: http://ustat.miur. it/dati/didattica/italia/atenei (accessed on 28 November 2020). 
69. Aversano, N.; Di Carlo, F.; Lucchese, M.; Sannino, G.; Tartaglia Polcini, P. Linee guida per il Bilancio di Genere negli Atenei italiani: Quali differenze rispetto alla prassi? In Proceedings of the SIDREA National Congress, University of Bari, Bari, Italy, 20 November 2020.

70. Censis. La Classifica Censis Delle Università Italiane (Edizione 2018/2019); Roma, Italy, 2018; Volume 3. Available online: https: / www. censis.it/sites/default/files/downloads/Classifica_Censis_2018-2019_delle_Universit\%C3\%A0_italiane.pdf (accessed on 28 November 2020).

71. Ministry of Education, University and Research. Dati per Bilancio di Genere. Available online: http://dati.ustat.miur.it/dataset/ dati-per-bilancio-di-genere (accessed on 25 January 2021).

72. Adams, C.A.; Harte, G. The changing portrayal of the employment of women in British banks' and retail companies' corporate annual reports. Account. Org. Soc. 1998, 23, 781-812. [CrossRef]

73. Bengtsson, M. How to plan and perform a qualitative study using content analysis. NursingPlus Open 2016, 2, 8-14. [CrossRef]

74. Hsieh, H.F.; Shannon, S.E. Three approaches to qualitative content analysis. Qual. Health Res. 2005, 15, 1277-1288. [CrossRef] [PubMed]

75. Vaismoradi, M.; Turunen, H.; Bondas, T. Content analysis and thematic analysis: Implications for conducting a qualitative descriptive study. Nurs. Health Sci. 2013, 15, 398-405. [CrossRef] [PubMed]

76. Graneheim, U.H.; Lundman, B. Qualitative content analysis in nursing research: Concepts, procedures and measure to achieve trustworthiness. Nurse Educ. Today 2004, 24, 105-112. [CrossRef] [PubMed]

77. Dey, I. Qualitative Data Analysis: A User Friendly Guide for Social Science; Routledge: London, UK, 1993. [CrossRef]

78. Krippendorff, K. Content analysis: An introduction to its methodology; Sage Publications Inc.: Thousand Oaks, CA, USA, 2004.

79. Catanzaro, M. Using qualitative analytical techniques. In Nursing: Research Theory and Practice; Woods, N.F., Catanzaro, M., Eds.; The CV Mosby Company: St. Louis, MO, USA, 1988; pp. 437-456.

80. Downe-Wambolt, B. Content analysis: Method, applications and issues. Health Care for Women Int. 1992, 13, 313-321. [CrossRef]

81. Patton, M.Q. Qualitative, Research E Evaluation Methods; Sage Publications Inc.: Thousand Oaks, CA, USA, 2002. 